THE TECHNOLOGICAL BASE OF THE NEW ENTERPRISE EDWARD B, ROBERTS MIT SLOAN SCHOOL OF MANAGEMENT 


\title{
THE TECHNOLOGICAL BASE OF THE NEW ENTERPRISE
}

\begin{abstract}
A flow model is hypothesized to explain the movement of technology by an entrepreneur from an outside "source organization" to form the initial technological basis for a new enterprise. Data from a longitudinal study of several hundred technological "spinoff" firms support the dominance of development in contrast with research work as the key source of the founding technology. Positive personal influences upon technology movement include longer employment at a "source" organization, advanced education at around the Master's level, and sensing an opportunity to exploit laboratory technology. Principal dissipating influences are personal aging of the entrepreneur and a delay between leaving the source and establishing the new firm.
\end{abstract}


The forty plus years since World War II have defined technological advance as an integral part of our society and a key basis for both military and industrial competition. Among other vital contributions, technology provides the raison d'etre for the formation and growth of myriad new firms. The opportunities presented by advancing technology, however, have not been seized by all potential entrepreneurs. The unique companies that are technology-based new enterprises were for the most part founded by individuals highly trained in existing technology. The new technical ventures have originated from similar technology-based organizational environments or sources.

All entrepreneurs must possess some sort of entrepreneurial spirit. Indeed increasing numbers of studies are examining the personal characteristics of entrepreneurs, especially those who are technology-based, and the nature of the organizations that incubate them. (Cooper, 1971; Roberts, 1968; Sexton and Smilor, 1986; Utterback et al., 1988; Van de Ven, Hudson and Schroeder, 1983) However, new technology-based companies are in addition dependent on the transfer of technology or technological knowhow learned or created by the entrepreneur. Although a few studies have addressed technological aspects of strategy for growing the young enterprise, (Meyer and Roberts, 1988; Romanelli, 1987) only rarely has the technical base of the firm at its time of origin been examined. (Roberts and Hauptman, 1986) This article provides a theoretical framework and empirical evidence on the determinants of the initial technological basis for these new enterprises.

\section{A THEORETICAL PERSPECTIVE}

Figure 1 presents a schematic (or flow model) of what might be involved in the personal generation and/or use of technology, here applied as the basis for a new firm. The diagram's elements constitute the set of hypotheses to be tested in this paper. First we assume there must necessarily be some technological knowhow worthy of transfer. This source of skills or knowledge might derive from several different cognitive realms in combination or separately (e.g., work experience, educational experience, the contents of a journal, knowledge of a friend). Every further step in the process leading to personally-transferred technology into a new firm builds from this first platform.

Next the information available at the source of technology must be 


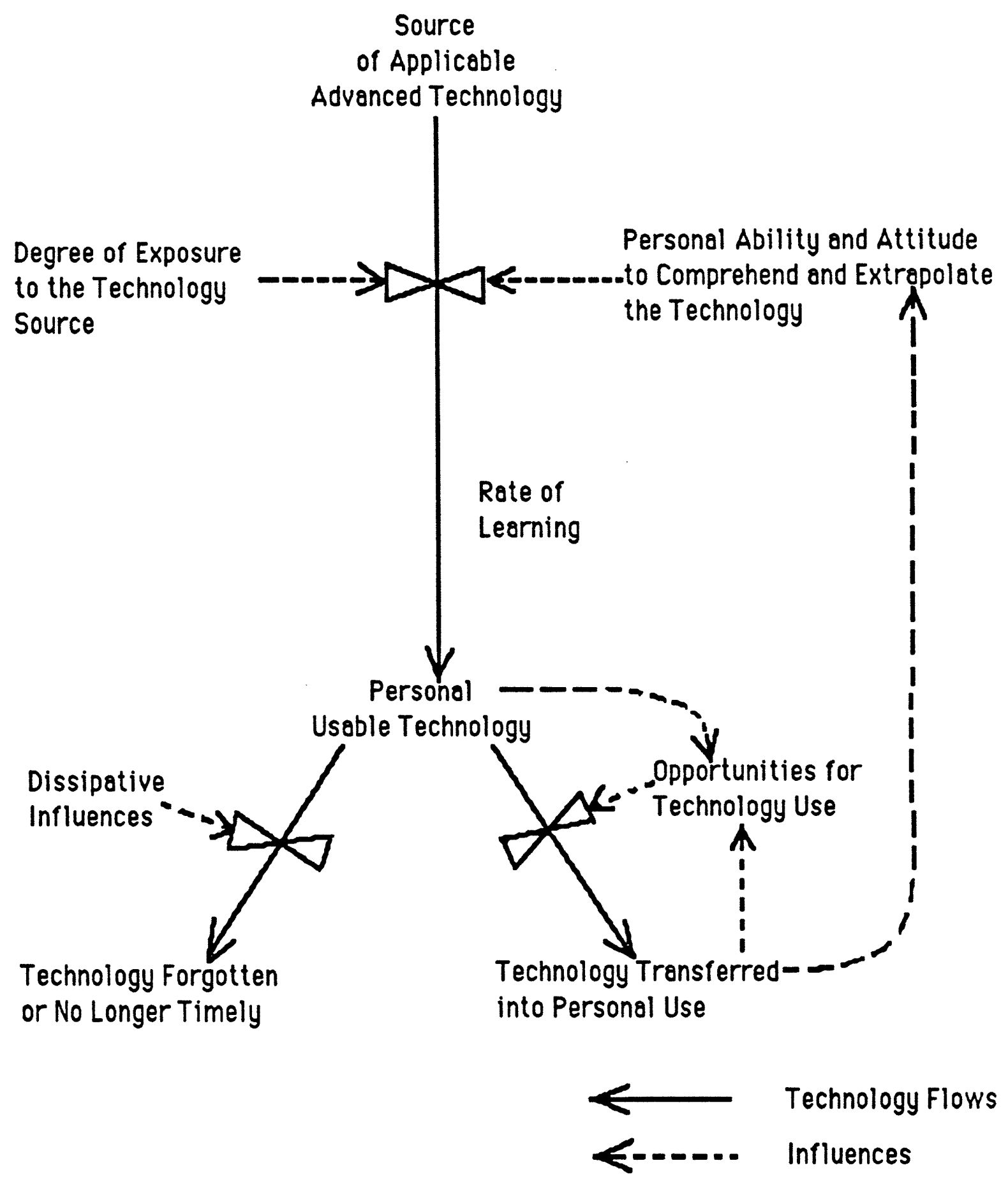

Figure 1. The Personal Transfer of Technology 
personally absorbed by an individual. To learn such technology an individual must be exposed to the source and have the ability and attitude to comprehend and perhaps interpret and apply the information. Length of exposure to a technology source is only one of several dimensions that potentially affect learning. The breadth of exposure, to knowledge creation as well as use, further influences the rate of possible learning.

Educational preparedness for learning must play a role in this transfer process. The layman has difficulties in acquiring knowledge of theoretical physics, even when opportunely exposed to excellent sources of such knowledge, without a prior grounding in physics or advanced mathematics principles. And attitudinal preparedness, a willingness and interest in absorbing new skills and tools, must also be present. Within the same organization, some delight in its stimuli and challenge; others are bored, and can't wait to get home.

These two influences, the degree of exposure to a source of potential new technology and the personal ability and attitude to comprehend the knowledge, combine in a not-well understood gating function to affect the individual scientist's or engineer's learning. The learning adds to the individual's storehouse of potentially usable technology. But the mere existence of personally accessible information is not sufficient for useful technology transfer to occur. Dissipative influences and lack of opportunity can block effective exploitation of potentially useful information. For example, continued lack of exposure to opportunities, or lack of ability to recognize opportunities, for application of his or her newly acquired knowhow no doubt causes the individual eventually to forget the technical knowhow. Or while not forgotten, the technology may cease to be as useful because problems for which it was once applicable no longer exist (or their priority has lessened). The technology obsoletes. Thus in time a pool of usable knowledge gradually shrinks unless replenished by new learning.

The final flow in this process, the one of objective interest to us, is the transfer of technology into use. The prime influence on this final stage of transfer appears a priori to be the opportunities for technology use, such as in the formation of a new enterprise. But second order influences are probably at work too. For example, the greater the base of usable technology the greater the likelihood of some matching between knowhow and application 
opportunity. But there is also increased likelihood that someone who has achieved useful techology transfer in the past accustoms himself to sensing new opportunities as they arise. That person is not only ready and waiting when opportunity knocks; he or she knows where to wait!

\section{SAMPLE SELECTION AND DATA COLLECTION}

The data analyzed here are part of a twenty years study of all aspects of the formation and growth of high-technology new enterprises, including more than 40 separate but related research studies. The data collected in thirteen of those studies (shown in Table 1) are used in this article, covering several hundred firms founded by former employees of MIT major laboratories and engineering departments as well as the former employees of a government laboratory, a major non-profit systems engineering organization and two large technological corporations.

Table 1. Spin-off Companies from Technological Source Organizations

Sources of New Enterprises

MIT major laboratories (4 studies) MIT academic departments (5 studies) Air Force Cambridge Research Laboratory MITRE Corporation Electronic systems company Diversified technological company

Totals
New Companies Identified

107

74

16

5

45

58

305
Participants in Besearch Study
96

60

15

5

Beginning with strong cooperation of senior managers in each source organization, initial lists were developed of suggested names of spin-off entrepreneurs from that organization. Follow-up interviews were used to screen these lists for inappropriate names as well as to generate further suggestions in a "snowball" sample creation process. Rigorous criteria were applied to include only those who had been former full-time employees of the 
source organizations, who later participated as founders of wholly-new for-profit companies. (As very few female entrepreneurs were found in these samples of technical entrepreneurs, the male pronoun will be used in the remainder of this article in referring to the entrepreneurs.)

Structured interviews with a detailed questionnaire, lasting typically one to two and one-half hours, were used to gather data from each entrepreneur personally, with telephone interviews used in less than ten percent of the cases and mailed interviews used only as a last resort in less than one percent of the cases. Some interviews stretched to seven or eight hours over two or three sessions! Despite extensive efforts to include all spin-offs from each source organization studied, no doubt some minor bias has crept into the sample of companies studied in that it is likely that any companies not located were less successful than those traced.

\section{INDICATORS AND MEASURES}

Answers to the detailed questionnaires led easily to the quantification of information. Most all of the answers were coded and arranged in computer data files. Incomplete information on some of the companies does not particularly affect the data analysis as relevant codes were given to isolate missing information. Conceptual and practical issues arose in measuring certain key elements in the studies, of which the most significant to the present article is the importance of the technology transferred from the source organization into the new enterprise.

\section{The Importance of Initial Transferred Technology}

The process of individual transfer of technology as outlined in Figure 1 presumably occurs to some extent whenever any new enterprise is begun. What is not so clear is the degree to which this transfer takes place and the role that specific organizations play in this process. The first issue we faced in gaining more insight into the process was the need for a simple measure of the degree of importance of initial technology transfer. Each company in our samples was rated on a four-point scale representing the extent to which it was dependent on technologies developed at the "source" laboratory under study. The rating was derived by observation of the circumstances surrounding the formation of the enterprise, by consideration of the nature of the company's products, and by the statements of the entrepreneur himself. 
As an initial trial of this way of assessing technological dependence, this measure was determined for one hundred and twenty-five MIT-based spin-off companies. For assuring the reliability of these trial ratings, two different coders evaluated a subset of the companies, with almost no disagreement between their classifications. In addition, the entrepreneurs' former laboratory supervisors were asked to rank the companies on this variable, as part of a separate backup study. Their classifications correlated significantly with those assigned by the coders $(p=.007)$. The intercoder reliability and the supervisor concurrence in this trial provided confidence in the use of this measure throughout our spinoff studies.

The importance of technology transferred from the source organization on the formation of the spin-off firms was divided into: Direct, partial, vague, and none. These degrees of importance of transferred technology are defined as follows:

Direct: The company in its present form would not have been started without the source-learned technologies. It now utilizes or utilized at the beginning mostly what the founder(s) learned at the source.

Partial: An important aspect of the company's work originated with source-learned technologies. The individual who transferred the technology might have supplemented the source-learned techologies at other employment between the laboratory and the new enterprise.

Vague: Nothing specific was transferred. However, general technical background and know-how learned at the source were very important. In this case, the company might have been started without the source experience.

None: Essentially nothing that the company does is related to source technologies. The individual who started the company may have learned an extensive amount at the source but he is not utilizing this (from a technological standpoint) in his new enterprise. 
The definitions utilized in the scale are specific to the source organizations under study. In other words a rating on importance of technology transfer for an MIT Lincoln Laboratory spin-off company relates only to the degree of dependence on Lincoln technologies. In addition, note that the terms "partial" and "vague" somewhat understate the importance of the source-learned technology in the formation of these new enterprises. In each of these categories, learned technology is unquestionably important; the difference is only in degree. Only the category of "none" dismisses the importance of the learned-technology.

As shown in Table 2 thirty-two new companies were directly affected by the learned technology, thirty-four partially, forty-three vaguely, and sixteen not at all. In all, then, one hundred and nine companies of these 125 felt the source-learned technology important to their creation.

Table 2. Degree of Importance of Technology Transfer ( $N=125$ MIT Spinoffs)

No. of

Companies

32

34

43

16

125
$\%$ of

Companies
Direct

Partial

Vague

None

Totals

\section{6}

27

34

13

$100 \%$

The distribution in Table 2 indicates that only 13\% of the companies had no technical dependence whatsoever on the spawning source laboratory, whereas $53 \%$ were critically or importantly dependent on laboratory-learned 
technologies. Some of the cases of "no transfer" arise from our tight definition of "spinoff", which forces inclusion in our samples of some companies in which the individual from "our" source organization was only a weak member of the founding group. Others are more straightforward in that the company is working in areas totally dissassociated from work carried on in the so-called "source" organization.

The importance of transferred technology from industrial source organizations was more varied than from the MIT labs and departments. "Direct" technological dependence accounted for only 16 percent of the electronic systems company's spinoffs, with "partial" transfer representing an additional 24 percent, according to the entrepreneurs' own estimates. These self-estimates may be prejudiced downward, however, due to entrepreneurs' concern about possible legal actions by the source industrial organization we had studied. The Legal Department of that electronics company told us of relationships with 12 of our studied 39 spinoffs, including lawsuits, licensing agreements, and formal waivers of rights to technology.

Most businesses educate large numbers of people in developing and using complex technology. But these firms usually do not want these people transferring outside the walls of the company the knowledge they have learned inside. The typical firm wishes to protect its huge investments by preventing this knowledge from leaving the company. Business is fearful of competitors acquiring knowledge of vital inside operations and proprietary technology. Many companies are just as concerned about the people who leave and utilize the technology they have learned to form profitable enterprises in competing or even non-competing areas. These attitudes are obviously quite different from MITs strongly positive orientation toward its science and technology being transferred out to benefit commerce, industry and society.

In the case of the spinoffs from the diversified technological corporation, the company was apparently unconcerned about the commercialization of spinoff technology. Indeed, 48 percent of its spinoff founders indicated that his company could not have started in its present form without technology from the parent ("direct transfer"), while 17 percent indicated partial technological dependence.

This discussion does not address the question of the financial value of this transferred technology. Nor does it treat what impact this initial 
technology might have on success or failure of the new firm. The latter issue will be addressed in later analyses of our new enterprise database.

\section{SOURCES OF ADVANCED TECHNOLOGY}

Having established that transferred technology serves as a critical base for many of the new enterprises, I begin here to test the model presented in Figure 1 and to present the results. Data do not exist to verify all elements of that implicit set of hypotheses, but much of the figure can be examined with information gathered from our research.

\section{Development Work}

Despite the fact that the source organizations studied all engaged in a broad spectrum of research and development work, I have shown elsewhere that technical entrepreneurs are especially biased in their orientation to developmental activities. (Roberts, 1968) Now I move the argument one step further to claim that development work, not research, is the much more fertile bed of immediately applicable advanced technology which potentially can become the basis for a new company. Only in the rare circumstances of a major breakthrough such as the transistor does research become the immediate basis for a product-oriented firm. Development in contrast takes research results and new technical knowledge and advances them toward and into application and use. Indeed the recent formation of numerous new firms in the biotechnology and genetic engineering field reinforces in a rather unique manner the evidence for this developmental dependency. All of the biotech firms have had to go through an extended and expensive research and development stage, post formation of the firm, in order to bring their prior knowledge base to a state of development adequate for product development and release.

To support this argument I examine first those entrepreneurs who had no delay between leaving the source labs and starting their own companies. Table 3 displays the level of technology transfer associated with the nature of work which the entrepreneur had performed at the source organization for fifty-one entrepreneurs who went immediately into their new enterprises. As their prior work becomes more developmental (i.e. as measured by increasing "Bullpup ratings" 1 from 1 to 9), both an increasing proportion of direct technology transfer occurs $(30 \%, 39 \%$, and $55 \%$, in order) as well as an 
increasing proportion of direct and partial technology transfer $(53 \%, 67 \%$, and $85 \%$, respectively). The type of work done at the source, the base for potential applicable technology, significantly affects the level of technology transfer into the new firm $(p=.025)$. Thus a double filter is at work: More development-oriented individuals become entrepreneurs, and more development-oriented entrepreneurs transfer more advanced technology immediately into their companies.

Table 3. Nature of Source Work and Technology Transfer for Immediate Company Founders ( $N=51)$

Nature of Work

("Bullpup Ratings)

$1-3$

$4-6$

$7-9$

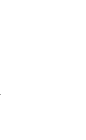

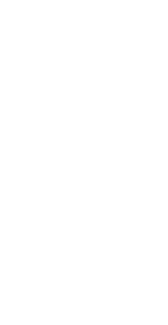

\footnotetext{
"Kendall Tau $=.25, p=.025$
}

Technology Transfer*

Direct Partial Vaque None

3

5

5

3

$\begin{array}{ll}4 & 2 \\ 5 & 1 \\ 3 & 0\end{array}$

Viewed slightly differently, research-oriented people who establish new companies have less work-derived technology to apply immediately in their new settings. They must draw from a broader array of other, mostly older, research results in order to generate a base for a new firm, or they must have longer time available, either prior to starting a firm or once the firm is underway, for their more recent research to be brought into development and application. This corresponds in direction but not degree to the Project Hindsight findings that little Department of Defense research had found its way into operational military use within a twenty-year period of the research being carried out. (Sherwin and Isenson, 1967)

1 The "Bullpup" measure of R\&D work content was developed by Chalmers W. Sherwin and Raymond S. Isenson as part of the DOD's "Project Hindsight". (Sherwin and Isenson, 1967) 
Another cut at our own data bolsters this argument. Table 4 shows the nature of source work vs. degree of technology transfer for those entrepreneurs who did delay after leaving the source before setting up their new firms. Researchers who wait have relatively more apparent opportunity for meaningful transfer than do development-types who wait. Research results "age" less rapidly than development; if anything, the research may become more relevant and applicable with time, whereas the development-stage work becomes more obsolescent and less applicable to the new firm. The Table 4 statistics support the direction of this effect, although not significantly.

Table 4. Nature of Source Work and Technology Transfer for Delayed Company Founders ( $N=41)$

Technology Transfer"

Nature of Work Direct-Partial Vague-None

Research

4

3

Development

(4-9)

12

22

DEGREE OF EXPOSURE

\section{Years at Source}

The amount of time the potential entrepreneur works at a source organization no doubt relates to the degee to which he learns and probably transfers that organization's technology into his new enterprise. Remember that the measure of degree of technology transfer really measures technical 
dependence. However, individual differences might produce differing patterns of learning over time. Some individuals are rapid learners, absorbing most of what is known within their environs quickly, reflected by the top curve in Figure 2. Others tend to have a more steady pace of knowledge absorption or even a pattern of learning that starts slowly and gradually accelerates, indicated by the two lower curves in Figure 2.

\section{Amount of Knowledge Learned}

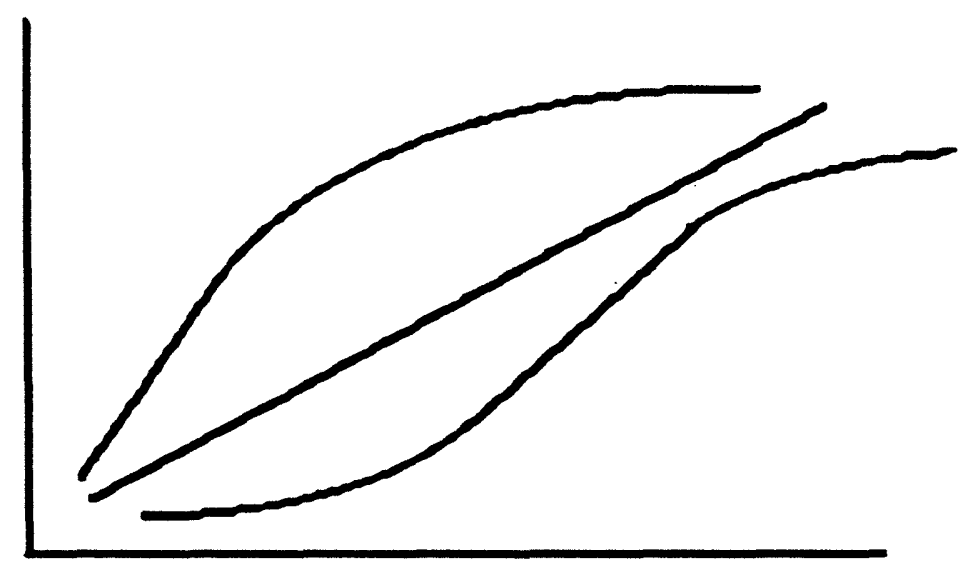

Time of Exposure

Figure 2. Possible Patterns of Individual Learning

Analysis of the relationship between the number of years a MIT-spinoff entrepreneur spent at the source laboratory and the degree to which he transferred its technology produces statistically significant results (Kendall $\mathrm{Tau}=0.17, p=.03$ ). Moreover, careful rechecking finds that this trend is linear, and not curvilinear, as the years of employment grow. Similarly, those electronic systems company spinoffs who spent longer in that company reported that their work at the lab caused them to learn more technology as opposed to just applying their prior knowledge $(p=.03)$; those longer employed entrepreneurs also transferred significantly more technology to their new enterprises than did their shorter employed colleagues $(p=.03)$.

\section{Part-Time Founding}

A second element of exposure relates to timing. Over half of the 
companies, perhaps a surprising number, were started on a part-time basis, "moonlighting" in the new firm while still working "full time" in the source organization. "Part-timers" have concurrent exposure to the needs of the new firm and the solutions from the prior (i.e., also still current) organization. Part-time entrepreneurs from MIT labs transferred more technology to their operations than full-time entrepreneurs $(p=.03)$. In the Massachusetts biomedical firms I studied the duration of part-time commitment was longer on average, 30 months, than in any other of my entrepreneurial samples. (Roberts and Hauptman, 1986) In those firms too, part-time founded companies had higher degrees of advanced technology coming from university and other source organizations $(p=.05)$. Logically, or selfishly, the part-time entrepreneur who is still working at a source laboratory should be trying to gain an advantage by making his efforts work for double purposes. He is more likely to transfer into his company technology related to lab projects on which he is currently working and ideas that are current in his laboratory. In attempting to conserve his efforts by using his laboratory endeavors to provide commercial possiblities, the part-time entrepreneur becomes an effective agent of technology transfer.

\section{PERSONAL ABILITY AND ATTITUDE}

One factor no doubt affecting learning rate is the individual's ability to perceive, comprehend and extrapolate the relevant technology. This suggests looking at the entrepreneur's education as a possible surrogate for technology transfer ability.

\section{Eormal Education}

But our measure of degree of technology transfer does not differentiate on relative sophistication of the technology, only on the receiving company's relative technological dependence. In any event formal educational attainment is not necessarily a valid representation of an individual's capacity to learn or of his acquired fund of knowledge. For example, in at least one new enterprise a technician with no formal education beyond high school supplied the technical basis for a sophisticated product in a new technological area for his company.

Despite these qualifications we tested the data for the association between educational level and technology transfer and found a weak positive 
relationship (Kendall Tau $=0.13, p=0.07$ ). Earlier analyses have shown that technical entrepreneurs seem to cluster around the Master's degree educational level. If that clustering also affected the degree of source technology exploited through transfer to the new firm, we should expect a quadratic relationship as pictured in Figure 3.

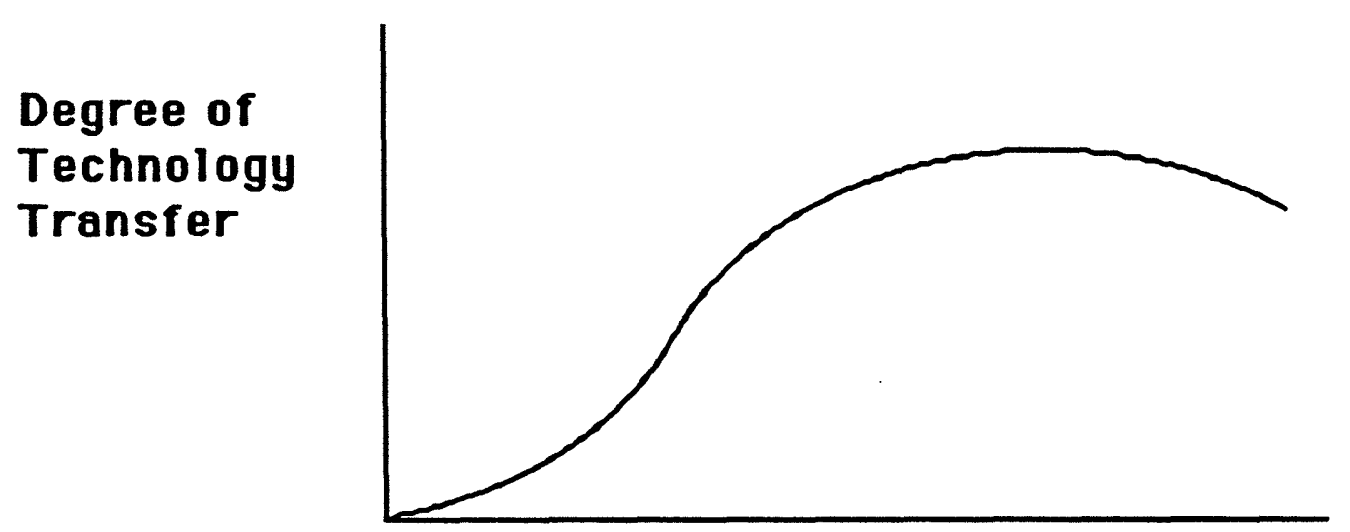

Educational Level

Figure 3. Possible Relationship between Educational Level and Technology Transfer

This hypothesis resulted in regrouping the data to separate moderately educated technical entrepreneurs from those with either lower or higher education, as indicated in Table 5, clustering the groups to equalize as closely as possible the totals around the margins. Statistical testing (i.e. the F-test) supports the notion that entrepreneurs with Master's degrees (more or less) transferred the most technology $(p=0.05)$.

Age

But just as education (up to a point) is supportive of an individual's ability to comprehend and his likelihood of transferring new technology, age may well suggest limitations on these abilities. Despite its controversial nature much evidence indicates that a person's technical abilities tend to 
Table 5 . Relationship between Grouped Educational Levels and Technology Transfer *

Educational

Level

Direct-Partial Vaque-None

Totals

Moderate education, i.e.

B.S. plus courses,

M.S., and

M.S. plus courses

33

24

57

Lower and higher education, i.e.

College without degree, and B.S., plus

Professional Engineering degree and Ph.D.

19

52
23

47 $\underline{42}$

99

"Group boundaries established to equalize as closely as possible the marginal totals.

peak between 30 to 40 years of age and begin to wane after that. In any event our earlier analyses have shown that the ages for entrepreneurial behavior have similar character. (Roberts and Wainer, 1971)

Logically, younger men, being closer to new technological developments and presumably more capable of grasping the complexities involved, seem likely to transfer more technology than older entrepreneurs. In Table 6 one hundred fifteen entrepreneurs are grouped according to their age at the founding of their companies and their level of technology transfer. The greatest proportion of direct and partial transfer occurs in the age range of 26-30 years; the lowest is in the range of 46-50. Direct and partial technology transfer decrease as age increases $(p=.03)$. Aging does appear to 
affect overall the extent of transferred technology.

Table 6. Age of Entrepreneur and Technology Transfer $(N=115)$

Technology Transfer*

$\begin{array}{rrrrr}\begin{array}{rrrr}\text { Age } \\ 21-25\end{array} & \text { Direct } & \text { Partial } & \text { Vaque } & \text { None } \\ 26-30 & - & - & 1 & - \\ 31-35 & 9 & 10 & 4 & 1 \\ 36-40 & 10 & 10 & 13 & 6 \\ 41-45 & 6 & 7 & 7 & 3 \\ 46-50 & 4 & 2 & 5 & 2 \\ >50 & - & 2 & 4 & 1 \\ & 2 & 2 & 2 & 2\end{array}$

"Kendall's Tau C=0.15, $p=0.03$

Further analyses of the data show that much of this effect arises from a reluctance of the older men who do eventually become entrepreneurs to leave the source lab and immediately set up their own companies. Those who leave the lab, take another job, and later start their own firm are older by the time they become entrepreneurs. But even within that group of delaying company founders (illustrated in Table 4) age is negatively and significantly correlated with technology transfer ( $T a u=-.26, p=.01)$.

Attitude 
Beyond issues of ability, an individual's attitude toward his or her work plays an important role in the learning process. A person who finds work challenging and enjoyable can be expected to learn more easily and develop skills more readily than a person who finds work boring or painful.

Additionally, a person who likes what he or she is doing would most probably want to continue that type of work in future employment (or self-employment!).

When applying this consideration to technology transfer, l expect that those entrepreneurs who had found their source work challenging and enjoyable would transfer more source technology into their new companies than those who did not. Table 7 shows how ninety-four entrepreneurs rated the challenge of their source work. The sole entrepreneur who felt his work was not challenging transferred none of the source's technology. Of the six entrepreneurs who felt the work minimally challenging (rating of 2), none had companies which directly involved the source technology and only one formed a company involving even partial transfer of source technology. As the rating of challenge increases, the proportion generally increases of direct and partial transfer of technology into the new enterprise. Forty-two percent of the individuals who rated the challenge of their source as 5 , directly or

Table 7. Challenge of Source Work and Technology Transfer ( $N=94)$

Challenge*

(No Challenge)

$\begin{array}{ll}\text { (No Challenge) } & 1 \\ & 2 \\ 3 \\ 4 \\ 5 \\ 6\end{array}$

(Very Challenging)

${ }^{\star T} \mathrm{Tau}=0.30, p=0.001$.
Technology Transfer *

Direct Partial Vague None

$\begin{array}{rrrrr}1 & - & - & - & 1 \\ 2 & - & 1 & 2 & 3 \\ 3 & 1 & - & - & - \\ 4 & 3 & 3 & 1 & - \\ 5 & 4 & 6 & 11 & 3 \\ 6 & 9 & 7 & 13 & 3 \\ 7 & 11 & 8 & 4 & -\end{array}$


partially transferred source technology into their companies. Fifty percent who rated the challenge as 6 , and over eighty percent who rated the challenges as 7 (very challenging), formed companies directly or partially dependent on source technology.

This same relationship was found between technology transfer and satisfaction with work. Table 8 displays data for ninety-seven entrepreneurs. As their ratings of satisfaction and enjoyment with their earlier source lab work experience rose from hate and dissatisfaction to much satisfaction and very enjoyable, an increasing proportion of the entrepreneurs transferred source technology directly or partially into their new companies $(p=.015)$. Beginning with the rating of 4 (neutral) and ending with that of 7 (much enjoyment and satisfaction), these proportions are forty-one percent, forty-one percent, fifty-one percent, and sixty-seven percent respectively.

\section{Table 8. Satisfaction and Enioyment of Source Work and Technology Transfer $(\mathrm{N}=97)$}

Satisfaction and Enioyment* Direct Partial Vaque None

(Much Dissatisfaction and Hate of Work)

Neutral

$\begin{array}{ll} & 5 \\ & 6 \\ \text { (Much Satisfaction) } & 7 \\ & \text { "Tau }=.21, p=.015\end{array}$

1
2
3

42

$5 \quad 2$

$6 \quad 13$

$7 \quad 11$

\section{Technology Transfer *}

Partial Vaque None

$\begin{array}{rrr}- & - & - \\ 1 & - & - \\ - & 1 & - \\ 4 & 1 & 3 \\ 8 & 2 & 6 \\ 11 & 17 & 3 \\ & 10 & 1\end{array}$

Since the challenge of the work and the satisfaction and enjoyment in 
doing the work are strongly related $(T a u=.60, p<.001)$, we can conclude that the entrepreneur's attitude toward his work has much to do with the level of technology he transfers into his new company. Furthermore, partial correlation analyses indicate that the link between challenge and transfer $(r=0.19)$ is far stronger than that between satisfaction and transfer $(r=0.04)$. It is worth noting in this regard that the causal relationship between technology transfer and perceived work satisfaction might be in the opposite direction. An entrepreneur who senses important transfer of technology from his previous job to his new enterprise might well more appreciate that prior job and express strong satisfaction with it.

\section{DISSIPATIVE INFLUENCES}

Thusfar we have presented a number of forces that contribute a base and learning to help establish the potential entrepreneur's usable store of technology. But technology doesn't remain ripe for plucking; some of it decays in utility by becoming less timely; other ideas or skills are just forgotten or lost over time.

\section{Years between Source and New Enterprise}

A common business practice is to have employees sign restrictive contracts which, among other things, usually forbid the employee upon termination of work with the company to work for a competing company or to enter into any business in which he can utilize the methods and knowledge he has acquired. This restriction generally holds for from one to three years after termination of employment. While many reasons are given for having this restrictive period, one of the prime reasons is that a company does not want an employee to use its technology to compete against it. By having a period of exclusion, companies feel that the employee's capability of effectively transferring company technology is considerably reduced.

The information collected on the spin-off entrepreneurs strongly supports this contention, even though many of the entrepreneurs came from university laboratories which did not follow these restrictive practices. Figure 4 shows the incidence of new enterprise formation over time, following departure from a source organization. Sixty-three of the one hundred twenty-one spin-offs in this grouping were formed immediately after the entrepreneur left the source or while he was still at the source. 
Figure 4. Rate of New Company Formation Related to the Number of Years after Termination of Employment ot the Source Organization
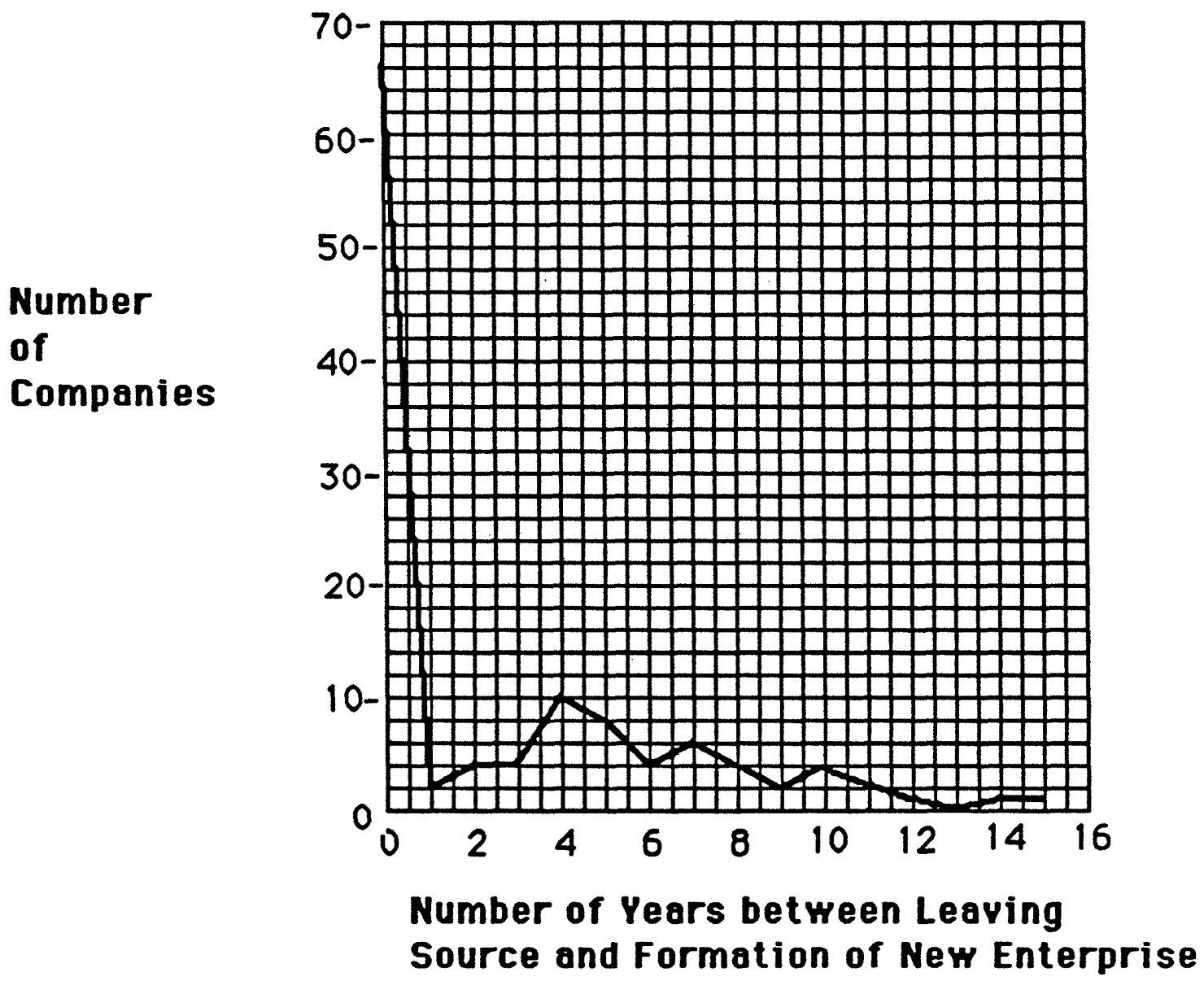
Eighty-five were formed within four years after leaving. In Table 9, one hundred eighteen of these companies were grouped by the time of company formation after termination of source employment and by their degree of technology transfer. The numbers displayed need little interpretation. Of

Table 9. Years between Source and New Enterprise vs. Technology Transfer $(\mathrm{N}=118)$

Technologv Transfer *

$\begin{array}{rcrrrr}\text { Number of Years * }^{*} & \text { Direct } & \text { Partial } & \text { Vaque } & \text { None } \\ \text { (Immediately) } & 0 & 25 & 19 & 13 & 5 \\ 1-2 & 2 & 3 & 2 & - \\ 3-4 & 3 & 6 & 4 & 2 \\ 5-6 & 1 & 3 & 6 & 2 \\ 7-8 & - & 1 & 9 & 1 \\ 9-10 & 1 & 1 & 1 & 3 \\ >10 & - & - & 3 & 2\end{array}$

${ }^{*} \mathrm{Tau}=.37, \mathrm{p}<0.001$

the thirty-two companies which directly utilized source technology, thirty were formed within four years after their founder left the source. Of the thirty-three which partially utilized source technology, twenty-eight were formed within four years after source employment was terminated. Viewing this in another way, thirty-six percent of the companies formed within four years directly utilized source technology and thirty-three percent of them partially utilized that technology. In comparison, only six percent of the companies formed after four years directly utilized source technology and only twelve percent partially utilized that technology. The relationship 
between time after leaving and transference of technology is very strong (Tau=.37, $p<0.001$ ).

The longer the time lag between leaving the source organization and setting up the new company, the less the degree of source-learned technology transferred $(p=.001)$. In the time elapsed the technological advantage that a scientist or engineer possesses at a frontier research and development organization is in part lost. As time passes the individual's technological knowhow from lab employment becomes irrelevant, and the degree of transfer necessarily decreases as time from the source lab increases.

The lost technological competitive advantage specifically reflects the relative advancedness of the "source" organization. Our data indicate that the prospective entrepreneur may reinforce rather than dissipate the knowledge he gained at a university or other advanced laboratory if he next works for another university or non-profit government-sponsored laboratory, rather than for a commercial concern. The degree of technology transfer is strongly but inversely related to the number of years of commercial experience between the source laboratory and the new enterprise. But practically no relationship whatsoever exists between the degree of technology transfer and the number of years of non-commercial experience between the laboratory and the new enterprise. Indirectly this notion supports the hypothesis that commercial experience has more of a decaying effect on the degree of source technology transfer to the new firm than does non-commercial experience. No data were collected on the importance of technologies transferred from the intervening organization(s) to the new enterprise.

\section{OPPORTUNITIES FOR TECHNOLOGY USE}

Nearly half of the spin-off entrepreneurs were indicated to have engaged in other activities between the time they left their source work and the time they formed their companies. Reasonably this group of entrepreneurs had different motives for leaving the sources and possibly were attracted to business ownership for different reasons than the group that left and immediately formed their companies. Surprisingly each group mentioned nearly identical reasons for leaving their source work, and both groups gave similar reasons for being attracted to business ownership.

\section{Iechnology as a Factor in Leaving}


The only differences which could be found among these entrepreneurs was the importance which the source technology played as a factor in their leaving the sources. Table 10 displays those data. Over half of the entrepreneurs (27 of 52) who left the sources and immediately formed their companies stated that the utilization of technology was the prime reason for their leaving. In comparison only twenty percent of the entrepreneurs ( 9 of 44) who formed their companies later stated technology utilization as an important factor. When asked if they would leave without the technology, seventy percent of the entrepreneurs who did not immediately form their companies said "yes" while only thirty-six percent of those who immediately entered their new ventures responded affirmatively.

Table 10. Technology as a Factor in Leaving Source Employment $(N=96)$

Question Immediately

Went Into Business

Immediately Later

Use technology as prime reason

for leaving source*

Yes No

Yes Ne

Would leave source without technology**

${ }^{*}$ Differences in groups: Chi Square $=8.77, p=.005$

**Differences in groups: Chi Square $=8.20, p=.005$

As would be expected, those entrepreneurs who stated that the use of laboratory technology was their prime reason for leaving transferred the greatest amount of technology to the companies they formed $(p=.001)$. They also had longer laboratory employment $(p=.02)$ and a shorter average time lag 
between leaving the lab and setting up their own company $(p=.002)$.

These findings are reflected nearly across the board in all the spin-off samples. Among the entrepreneurs who left the electronic systems company, many had received patents for advancing laboratory technology. Those patent holders transferred significantly more technology to their new firms $(p=.04)$, sometimes with licenses from the source corporation, an explicit form of recognition of opportunities inherent in the new technology. Another example of identifying opportunities for technology use is provided by 60 percent of the spin-offs started directly from the diversified technological corporation, where the founder's decision to start a company depended on his knowledge of a product or service that he felt was not being adequately developed or commercialized by the source. In these cases, each founder usually took some or all of the product's technology with him to the new business, usually by agreement with the source corporation.

\section{SUMMARY}

This article has explained empirically the technological basis for the spin-off new enterprise. A conceptual model was presented of a variety of influences upon the flow of technology from an advanced research and development "source organization" into a newly founded company. The measure used to assess the final technology transferred is a four-point scale of importance of the technology to the new firm: Direct, partial, vague, and none. Evaluating the spin-offs with this measure generates a broad distribution of outcomes, with the highest manifested technology transfer affecting about one-quarter of the new companies.

The results of "hypotheses testing" of the Figure 1 model are synopsized in Table 11. Development-oriented work at the source organization, not research work, is shown to be the primary origin for most of the transferred technology. A double filter is in effect: More development-oriented individuals become entrepreneurs, and more development-oriented entrepreneurs transfer technology immediately into their own firms.

Greater exposure to the technological source through longer years of service at the labs leads to more technology transferred to the new company. This effect is supplemented if the entrepreneur starts his company on a "moonlighting" basis, working part-time in the new enterprise while 
continuing "full-time" in the source lab.

Personal ability to perceive, understand and apply advanced technology, manifested by an advanced formal educational level, is seen to be supportive of entrepreneurial technology transfer, although some negative effects seem to be provided by Ph.D.-level education. Somewhat countering the positive influence of education is the negative influence of aging, especially beyond the age of 40 , on transferring source-learned technology to the new company.

Individual attitudes reinforce abilities. Those who see their former source organization's work as challenging and satisfying seem to find and transfer more technology to their own startups, although obvious success in technology transfer might enhance one's feelings of satisfaction with a prior employer.

Far more significant than personal aging, the principal dissipative influence on technology transfer is a delay between terminating employment at a source organization and establishing the new enterprise. The decaying effect on the technological basis of the company is strong and nearly immediate, essentially full dissipation of transferability occurring within four years after departure.

Finally, those who identify utilization of some technology as the prime reason for leaving the source organization make highly important transfers to their new firms. They sense and immediately attempt to commercially apply an advanced technology.

It is critical to point out in closing that few of the entrepreneurs left their sources with a product that had actually been developed at work. The technology transferred was advanced knowledge that they had learned and then applied in the creation of their new enterprises. The effects of this technology transfer upon the success of the new firm will be discussed in later work. 
Table 11. Characteristic Influences on Technology Transferred to the New Enterprise

Source of Advanced Technology

Development-oriented work at source organization

Exposure to the Technology

Length of service at source

Part-time founding

Personal Ability and Attitude

Moderate educational level

Negative effect of aging

Sense of challenge and satisfaction with source

Dissipative Influence

Years between source and new enterprise

Qpportunities for Technology Use

Technology as prime reason for departure 


\section{REFERENCES}

Cooper, Arnold C.

1971 "Spin-offs and technical entrepreneurship." IEEE Transactions on Engineering Management, EM-18(1), 2-6.

Meyer, Marc H. and Edward B. Roberts 1988 "Focusing product technology for corporate growth." Sloan Management Review, 29, 7-16.

Roberts, Edward B.

1968 "Entrepreneurship and technology: A basic study of innovators." Research Management, 11, 249-266.

Roberts, Edward B. and Oscar Hauptman 1986 "The process of technology transfer to the new biomedical and pharmaceutical firm." Research Policy, 15, 107-119.

Roberts, Edward B. and Herbert A. Wainer 1971 "Some characteristics of technical entrepreneurs." IEEE Transactions on Engineering Management, EM-18(3), 100-108.

Romanelli, Elaine 1987 "New venture strategies in the minicomputer industry." California Management Review, 30, 160-175.

Sexton, Donald L. and Raymond W. Smilor 1986 The Art and Science of Entrepreneurship. Cambridge, MA: Ballinger Publishing.

Sherwin, Chalmers W. and Raymond S. Isenson 1967 "Project Hindsight", Science, 156, 23 June, 1571-1577.

Utterback, James M., Marc Meyer, Edward Roberts and Goren Reitberger 1988 "Technology and industrial innovation in Sweden: A study of technology-based firms formed between 1965 and 1980." Research Policy, 17, 15-26.

Van de Ven, A.H., R. Hudson and D.M. Schroeder 
1983 "Designing new business startups: Entrepreneurial, organizational, and ecological considerations." Journal of Management. 